\title{
The Operant Plantar Thermal Assay: A Novel Device for Assessing Thermal Pain Tolerance in Mice
}

\author{
Ashlie N. Reker, Sisi Chen, Katherine Etter, Taylor Burger, Makayla Caudill, and Steve Davidson
}

https://doi.org/10.1523/ENEURO.0210-19.2020

Department of Anesthesiology and Pain Research Center, University of Cincinnati, College of Medicine, Cincinnati, $\mathrm{OH} 45267$

\begin{abstract}
Pain is a multidimensional experience of sensory-discriminative, cognitive, and affective processes; however, current basic research methods rely heavily on response to threshold stimuli, bypassing the supraspinal processing that ultimately gives rise to the pain experience. We developed the operant plantar thermal assay (OPTA), which utilizes a novel, conflict-based operant task requiring evaluation and active decision-making to obtain reward under thermally aversive conditions to quantify thermal pain tolerance. In baseline measures, male and female mice exhibited similar temperature preferences, however in the OPTA, female mice exhibited greater temperature-dependent tolerance, as defined by choice time spent in an adverse thermal condition to obtain reward. Increasing reward salience (4\% vs $10 \%$ sucrose solution) led to increased thermal tolerance for males but not females. To determine whether neuropathic and inflammatory pain models alter thermal tolerance, animals with chronic constriction injury (CCl) or complete Freund's adjuvant (CFA), respectively, were tested in the OPTA. Surprisingly, neuropathic animals exhibited increased thermal tolerance, as shown by greater time spent in the reward zone in an adverse thermal condition, compared with sham animals. There was no effect of inflammation on thermal tolerance. Administration of clonidine in the $\mathrm{CCl}$ model led to increased thermal tolerance in both injured and sham animals. In contrast, the non-steroidal anti-inflammatory meloxicam was anti-hyperalgesic in the CFA model, but reduced thermal pain tolerance. These data support the feasibility of using the OPTA to assess thermal pain tolerance to gain new insights into complex pain behaviors and to investigate novel aspects of analgesic efficacy.
\end{abstract}

Key words: analgesia; inflammatory pain; neuropathic pain; novel methods; operant learning

\section{Significance Statement}

The translation of novel pain management techniques has been hindered, in part, by reliance on pre-clinical models that do not to measure the multidimensional experience of pain. Here we present a novel device and protocol to assess pain tolerance in the mouse. We show that pain tolerance is a dynamic behavior influenced by sex, that hypersensitivity does not necessarily predict pain tolerance, and that analgesics that reduce hypersensitivity may not enhance pain tolerance. This approach increases the capability to pursue new directions in basic pain research.

\section{Introduction}

Chronic pain, as a primary condition and sequela, is a leading cause of global morbidity and disability (Rice et al., 2016). Current treatments for pain are often

\footnotetext{
Received May 31, 2019; accepted January 31, 2020; First published February 18, 2020.

The authors declare no competing financial interests.
}

ineffective, possess unwanted side-effects, and carry the potential for abuse, as exemplified by the high number of opioid-related deaths (Dart et al., 2015; Rudd et al., 2016). Despite the recognition of pain relief as a major health

Author contributions: A.N.R. and S.D. designed research; A.N.R., S.C., K.E., T.B., and M.C. performed research; A.N.R. contributed unpublished reagents/ analytic tools; A.N.R. and S.D. analyzed data; A.N.R. and S.D. wrote the paper. 
care and research priority (Institute of Medicine, 2011), the translation of novel, non-opioid analgesics to the clinic continues to exhibit low rates of success. Myriad reasons for the lack of new, safe, and efficacious analgesics have been hypothesized (Vierck et al., 2008; King and Porreca, 2014). Here, we address the concern that the most frequently used tests of nociception in animal models, i.e., measures of reflexive withdrawal to threshold stimuli, are incomplete proxies for the human chronic pain experience.

Pain is a multidimensional experience, comprised of sensory-discriminative, affective, motivational, and cognitive components, which are generated by the brain (Melzack, 1999; Price, 2000). Given that reflexive withdrawal can occur with a latency preceding conscious perception of the stimulus (Fendrich et al., 2004; Vierck and Yezierski, 2015) and occurs in decerebrate organisms (Woolf, 1984), reflexive measures alone cannot produce a complete picture of pain processing. Alternatively, non-reflexive methods of modeling and assessing pain behaviors have been developed including, real-time and conditioned-place preference and aversion, the grimace scale, and naturalistic/ home cage behaviors, which may capture additional aspects of the multidimensional components of pain (Labuda and Fuchs, 2000; Walczak and Beaulieu, 2006; King et al., 2009; Langford et al., 2010; Urban et al., 2011; Jirkof, 2014; Kandasamy et al., 2016). However, these tests do not capture the dynamic ability to endure pain to achieve a deliberate goal, or pain tolerance, a critical and familiar feature on the spectrum of human pain experience. The neural substrates of pain tolerance therefore remain poorly understood despite the potential for enhanced pain tolerance to be a clinically effective therapeutic strategy, especially for individuals coping with chronic pain.

We designed and constructed a novel, inexpensive device and developed a behavioral protocol to quantify pain tolerance in mouse models through an investigator-independent and un-biased operant task. The operant plantar thermal assay (OPTA) utilizes operant learning and decision-making within an approach-avoidance conflict paradigm to establish the duration and intensity of a noxious stimulus an animal will withstand to obtain a reward. Here we establish the parameters at which the OPTA can be used to determine baseline thermal pain tolerance. We test whether thermal pain tolerance is a dynamic behavior influenced by sex, motivation, and analgesics in neuropathic and inflammatory models of pain. We further demonstrate the effects of common analgesics on thermal pain tolerance behavior under this conflict paradigm. These experiments illustrate the utility of the OPTA as a practical tool to establish and modulate pain tolerance behavior, which can

This work was supported by The American Pain Society, Rita Allen Foundation, and the National Institutes of Health T32 Training Grant G100122626340400111013597.

Correspondence should be addressed to Steve Davidson at davidsst@ ucmail.uc.edu.

https://doi.org/10.1523/ENEURO.0210-19.2020

Copyright (C) 2020 Reker et al.

This is an open-access article distributed under the terms of the Creative Commons Attribution 4.0 International license, which permits unrestricted use, distribution and reproduction in any medium provided that the original work is properly attributed. be used to complement standard threshold-level nociceptive testing.

\section{Materials and Methods}

\section{OPTA: apparatus}

The floor of the OPTA is made of two 12 " $\times 6$ " $\times 1 / 4$ " aluminum plates (3003, MetalsDepot), which are fixed to a cold plate peltier (Cold plate cooler, CP-061, TE Technology) using MX4 Thermal Conductive Paste (Arctic) and countersunk screws (M4 machine screws), then joined using nonconductive PL Premium Polyurethane construction adhesive (Loctite). Each Peltier is independently controlled by a power supply (PS-12-8, 4A, TE Technology) and temperature controller (TC-48-20, TE Technology). A thermistor delivers real-time feedback to the temperature controller, allowing precise thermal regulation of the floor. A $1 / 4$ " thick acrylic (SourceOne) enclosure surmounts the apparatus. This enclosure is divided into two equally sized chambers $(5.5$ " $\times 5.5$ " $\times 12$ ") by placing a wall $(1 / 4 " \times 4 " \times 12 ")$ at the midpoint of the enclosure creating a narrow, 1.5 " wide passageway to allow movement between the chambers. Two equidistant holes are drilled through the rear wall of the acrylic enclosure through which the spouts of water bottles are mounted. To circumvent the potential confound of object novelty, spouts matched those used in the home cage. One bottle was empty (null zone), the other contained a $4 \%$ sucrose solution (reward zone), which is innately rewarding to mice and widely used in appetitive operant conditioning paradigms (Lewis et al., 2005). Zone areas of $\sim 1.75^{\prime \prime} \times 2.5 "$, were defined within ANYmaze software (Stoelting) and positioned at the furthest distance from the entry point between the chambers. The zone area was such that only the head of the mouse could occupy the space. Video recording was from an overhead mounted camera (Logitech) using the "headtracking" function in ANY-maze. Animals were placed in the null side at the start of each training and testing session. Location of null and reward sides remained constant through all experiments. This paradigm presents an approach-avoidance conflict wherein the animal must choose between obtaining a reward by traversing an experimentally determined aversive temperature, or forgo reward. Accumulated time in the reward zone was considered a measure of reward seeking behavior. See Figure 1 for additional apparatus details.

\section{Animals}

Adult (8- to 12-week-old) male and female C57BL/6J mice were housed four per cage. Food and water were available ad libitum, except as described. Facilities were maintained at $\sim 22 \%$ humidity and $22^{\circ} \mathrm{C}$ on a $12 / 12 \mathrm{~h}$ light/dark cycle. Testing occurred during the light cycle. Animal testing procedures and handling complied with the ethical guidelines and standards established by the Institutional Animal Care and Use Committee in compliance with the Guide for Care and Use of Laboratory Animals [National Research Council (U.S.), 2011]. 
A

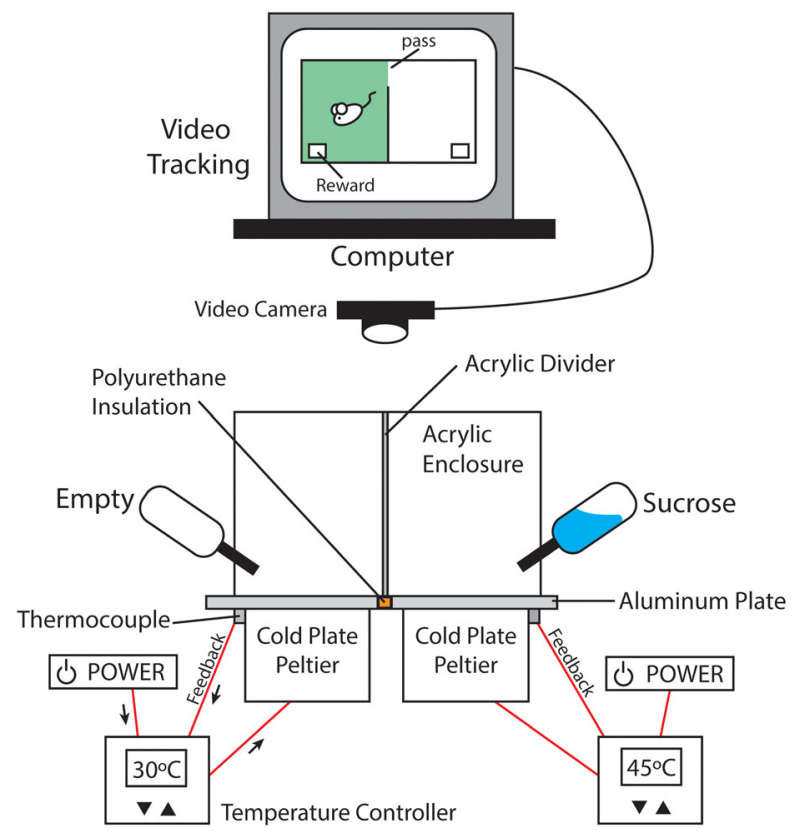

B

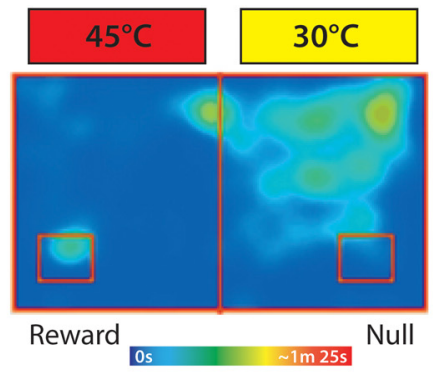

C

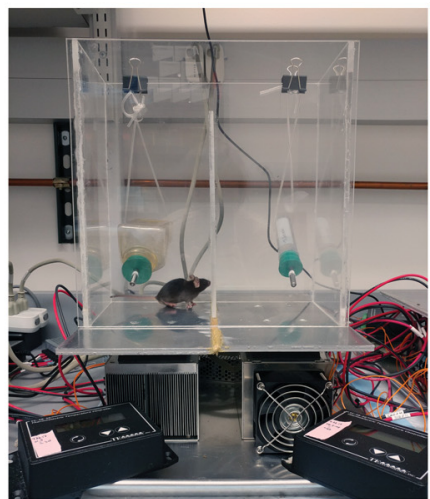

Figure 1. OPTA apparatus and animal tracking. $\boldsymbol{A}$, Schematic of the OPTA. Each power supply runs both a Peltier and a temperature controller. The temperature controller receives feedback from a thermode attached to the aluminum plate, allowing independent real-time thermal control. The acrylic enclosure creates a choice paradigm by isolating each floor into chambers between which a narrow pass exists. The video system tracks the head of the animal. $\boldsymbol{B}$, A representative heatmap illustrating the approach-avoidance conflict. The majority of activity is seen on the null $\left(30^{\circ} \mathrm{C}\right)$ side, with increased activity apparent at pass point between chambers, while activity in the aversive reward side is largely limited to the reward zone. $\boldsymbol{C}$, Photograph of the OPTA in operation.

\section{Pain models}

Neuropathic pain was induced using a modified chronic constriction injury $(\mathrm{CCl})$ of the left sciatic nerve performed under isoflurane anesthesia, wherein three ligations were applied to the nerve using $6-0$ chromic gut, until a brief twitch of the surrounding muscle was seen (Bennett and Xie, 1988; Taves et al., 2016). Control sham surgery for $\mathrm{CCl}$ required the nerve be only located and freed. Muscle and skin of both groups were closed with sutures or Vetbond. To establish hypersensitivity, threshold testing was performed on day 7 postoperative, coinciding with OPTA test day. Inflammatory pain was modeled by administering $10 \mu \mathrm{l}$ of complete Freund's adjuvant (CFA; Thermo Fisher Scientific) into the plantar surface of the left hind paw 24-48 h prior to testing, as described previously (O'Brien et al., 2015). The control for CFA was a saline injection of equivalent volume. All experiments assessing pain models used only male mice in light of initial results with the OPTA.

\section{Analgesic models}

For all experiments, an equivalent volume of $0.9 \%$ biological saline (Hospira Inc) was injected as vehicle control. The $\alpha 2$-agonist, clonidine (Sigma-Aldrich) was administered intrathecally at a concentration of $0.1 \mu \mathrm{g} / 5 \mu \mathrm{l}$ in a total volume of $5 \mu \mathrm{l}$ to animals having received $\mathrm{CCl}$ or sham, as described previously (Hylden and Wilcox, 1980; Fairbanks, 2003). This dose did not induce motor dysfunction in mice (Stone et al., 2014). Investigators were blind to treatment for experiments measuring the effect of vehicle and clonidine in sham versus $\mathrm{CCl}$. The nonsteroidal anti-inflammatory, meloxicam (Henry-Schein), was administered subcutaneously, into the nape of the neck, at $2 \mathrm{mg} / \mathrm{kg}$ (Kolstad et al., 2012). Testing was conducted in the OPTA using a $40^{\circ} \mathrm{C}$ reward zone. The effects of meloxicam versus vehicle on pain tolerance in animals having received CFA or control plantar injection was assessed.

\section{Radiant heat withdrawal assay}

A modified Hargreaves test (Hargreaves et al., 1988) was used to assess threshold response to a localized radiant heat source applied to the ventral surface of the left hind paw. Animals were habituated in an acrylic box $(4 " \times 4 " \times 6$ ") situated on top of a tempered glass surface (30" $\times 12$ " $\times 1 / 4$ "; IITC). Animals were acclimated to testing conditions for $\sim 60 \mathrm{~min}$, after which, a beam of radiant heat was concentrated on $4 \times 6 \mathrm{~mm}$ spot of the plantar surface of the hind paw. Time to withdraw from the stimulus was measured as an indication of thermal threshold (Cheah et al., 2017).

\section{Analysis}

The principle measure of interest from the OPTA was time spent in the reward zone. Distance traveled was also recorded to assess mobility; $t$ tests (two-tailed), were conducted to assess differences in thermal preference, 

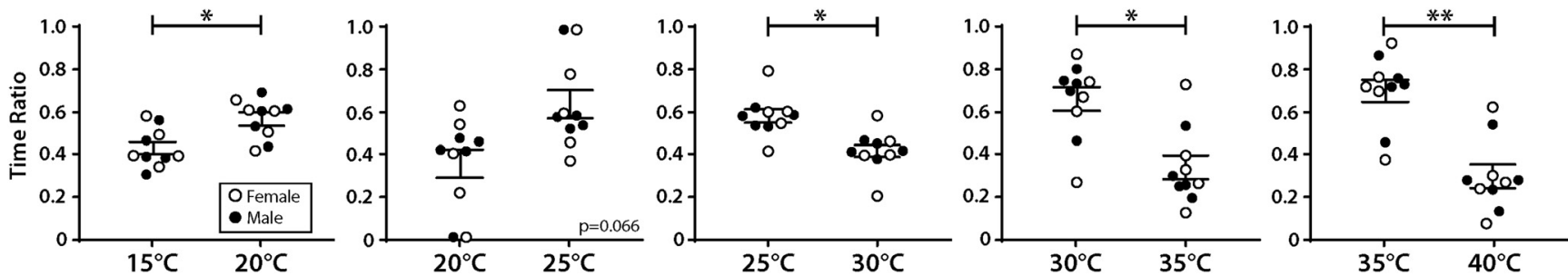

Figure 2. Thermal preference of adult naive wild-type mice, no reward. Naive male $(n=5)$ and female $(n=5)$ mice were monitored for $900 \mathrm{~s}\left(600 \mathrm{~s}\right.$ for $\left.35 / 40^{\circ} \mathrm{C}\right)$ on pseudo-randomly presented paired-temperature preference tests. Ratio of time spent in each chamber per test is shown. No between sex differences were detected. Paired $t$ test (two-tailed). Data are presented as mean \pm SEM, $* p \leq 0.05, * * p \leq 0.01$.

thermal threshold, reward seeking, learning and extinction, distance traveled, pooled comparisons, and time in reward zone. ANOVA was used to explore the effect of training day, impact of sex, sucrose concentration, temperature, pain, and pain with analgesia on time spent in the reward zone, thermal threshold, and distance traveled. Pearson correlation assessed time in reward zone with sucrose consumption. Where appropriate, Tukey's or Sidak's post hoc tests were conducted to determine significance. All analyses were done using GraphPad Prism 7; $\alpha=0.05$ was set as the determinant of significance. Data are reported as mean \pm SEM.

\section{Results}

\section{Baseline thermal preference}

Side bias was assessed for female and male mice during a 10-min free exploration of the OPTA with two empty bottles present. Neither females nor males displayed a side preference $\left(t_{(30)}=0.6, p=0.55\right.$, males and females combined, data not shown). To establish the thermal preference of wild-type, naive female and male mice in the OPTA, five free choice tests were performed, wherein animals were given $900 \mathrm{~s}$ to freely explore the OPTA with floor temperature pairings of $15 / 20^{\circ} \mathrm{C}, 20 / 25^{\circ} \mathrm{C}, 25 / 30^{\circ} \mathrm{C}$, and $30 / 35^{\circ} \mathrm{C}$. A reduced test time of $600 \mathrm{~s}$ was set for $35 / 40 \mathrm{C}^{\circ}$ to prevent the possibility of undue discomfort to the animals. No bottles were present during these tests. Preference or aversion was measured as proportion of total test time spent in each chamber. The chamber in which significantly less time was spent was interpreted as thermally aversive.
Within sex preferences (data not shown) indicated that female mice did not prefer any temperature significantly across the five experimental conditions. Male mice displayed a preference for $25^{\circ} \mathrm{C}$ in the $25 / 30^{\circ} \mathrm{C}$ condition $\left(t_{(4)}\right.$ $=4.32, p=0.01) ;$ a preference for $30^{\circ} \mathrm{C}$ in the $30 / 35^{\circ} \mathrm{C}$ condition $\left(t_{(4)}=3.25, p=0.03\right)$; and a preference for $35^{\circ} \mathrm{C}$ in the $35 / 40^{\circ} \mathrm{C}$ condition $\left(t_{(4)}=3.05, p=0.04\right)$. Overall, male and female mice displayed the same pattern of thermal preference, with no between-sex difference. As there was no difference between sexes at any given temperature, data were combined to assess overall thermal preference (Fig. 2). Overall, $20^{\circ} \mathrm{C}$ was preferred to $15^{\circ} \mathrm{C}\left(t_{(9)}=\right.$ 2.36, $p=0.04) ; 25^{\circ} \mathrm{C}$ to $30^{\circ} \mathrm{C}\left(t_{(9)}=2.74, p=0.02\right) ; 30^{\circ} \mathrm{C}$ to $35^{\circ} \mathrm{C}\left(t_{(9)}=2.88, p<0.02\right)$; and $35^{\circ} \mathrm{C}$ to $40^{\circ} \mathrm{C}\left(t_{(9)}=3.82\right.$, $p=0.004$ ). Based on these results, future experiments set the null side of the OPTA to $30^{\circ} \mathrm{C}$, as the approximate midpoint between $43^{\circ} \mathrm{C}$ and $15^{\circ} \mathrm{C}$, the thermal thresholds for acute activation of nociceptors (Bautista et al., 2007; Julius, 2013; Zheng, 2013; Tékus et al., 2016), allowing the broadest dynamic range for testing.

\section{Training}

We next established the number of trials required for female and male naive mice to attain a stable baseline level of time in the reward zone (Fig. 3). Mice were food and water restricted for $4-5 \mathrm{~h}$ prior to a $30-\mathrm{min}$ free-choice task with both floors set to $30^{\circ} \mathrm{C}$ and $4 \%$ sucrose available in the reward zone, while an empty water bottle was in the null zone. There were a total of four sessions, each separated by 24 h. Female mice showed no significant difference in time spent in the reward zone across $4 \mathrm{~d}$ of
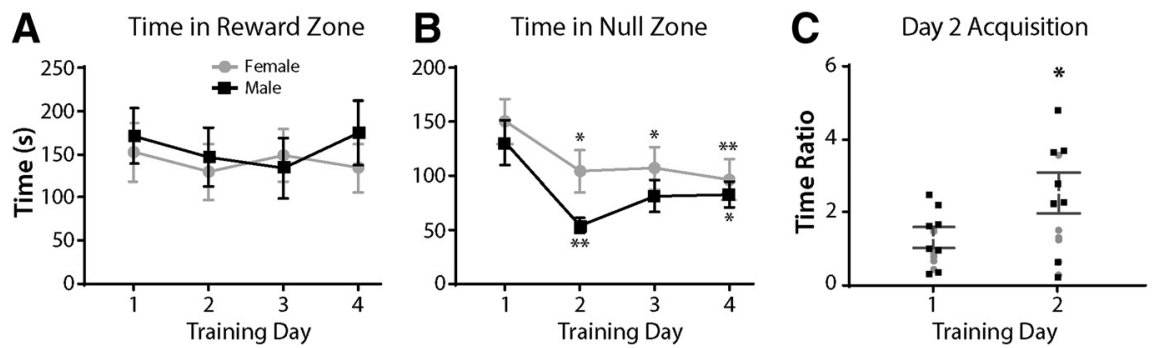

Figure 3. Training for operant acquisition. $\boldsymbol{A}$, Female $(n=8)$ and male $(n=8)$ mice showed no difference in time spent in reward zone across $4 \mathrm{~d}$ of training, one-way ANOVA with Tukey's correction. $\boldsymbol{B}$, Female and male mice decreased time spent in the null zone after the first training day, one-way ANOVA with Tukey's correction. All significances are in comparison with day 1. $\boldsymbol{C}$, Female and male mice show an increase in ratio of time spent in the reward compared with null zone on day 2 of training, unpaired $t$ test (twotailed). Data are presented as the mean \pm SEM; $* p \leq 0.05, * * p \leq 0.01$. 

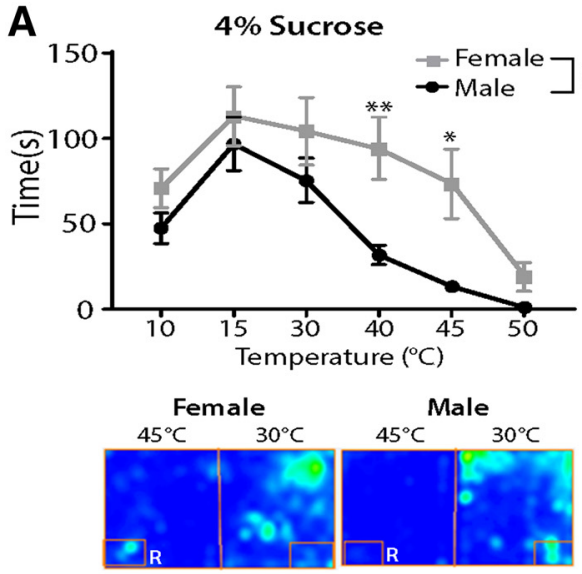

D Time in $30^{\circ} \mathrm{C}$ Reward Zone

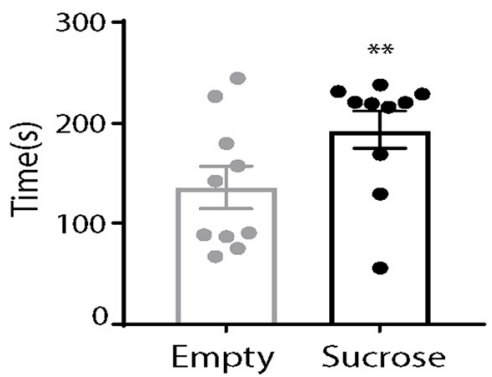

B
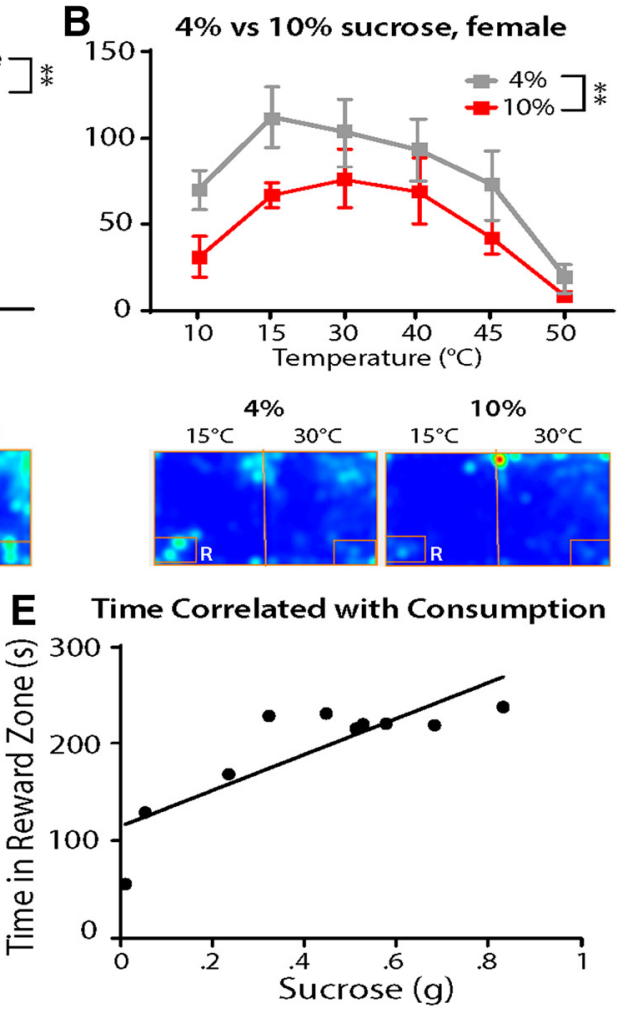

Time Correlated with Consumption
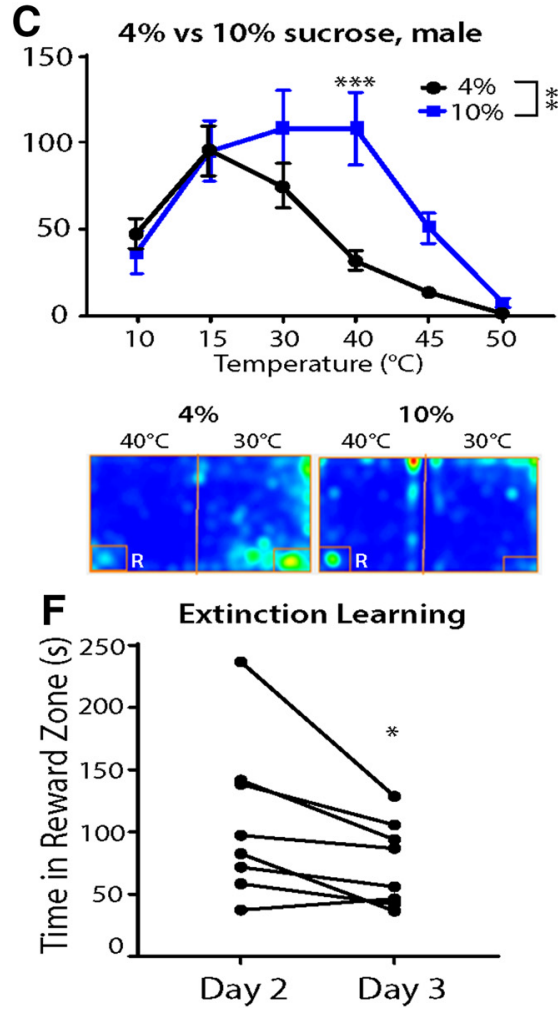

Figure 4. Temperature-dependent tolerance is affected by sex and reward salience. $\boldsymbol{A}$, Female $(n=8)$ and male $(n=8)$ mice differed in their tolerance to temperatures in the OPTA with $4 \%$ sucrose reward. Below, Representative heat maps of female and male mice in $30 / 45^{\circ} \mathrm{C}$ test. $\boldsymbol{B}$, Male mice increased tolerance to aversive temperatures when $10 \%$ sucrose was available $(n=7)$ compared with a reward of $4 \%$ sucrose $(n=8)$. Below, Representative heat maps of $4 \%$ and $10 \%$ sucrose conditions. $\boldsymbol{C}$, Female mice $(n=8)$ exhibited reduced time in the reward zone when the reward was $10 \%$ sucrose compared with a reward of $4 \%$ sucrose across temperatures. Below, Representative heat maps of $4 \%$ and $10 \%$ sucrose conditions. $\boldsymbol{D}$, Male mice $(n=10$ per group) spend more time in reward zone when $4 \%$ sucrose is present compared with when an empty bottle is present, unpaired $t$ test (two-tailed). Furthermore, time spent in reward zone is significantly positively correlated with sucrose solution consumption. $\boldsymbol{E}$, Pearson correlation, $y=185.4+114.8$. $\boldsymbol{F}$, Upon removal of the reward, male mice spend less time in the reward zone, paired $t$ test (two-tailed). Note, male and female mice in $4 \%$ sucrose condition served as sex and age matched control for $10 \%$ sucrose condition. $\mathrm{R}=$ reward zone. A-C, Two-way ANOVA with Sidak's correction. Data are presented as the mean $\pm \mathrm{SEM} ; * p \leq 0.05, * * p \leq 0.01, * * * p \leq 0.001$.

training $\left(F_{(2.641,18.49)}=0.88, p=0.457\right)$, nor did male mice $\left(F_{(1.714,12)}=1.754, p=0.215\right.$; Fig. 3A). However, females and males exhibited an effect of training day on time spent in the null zone $\left(F_{(2.198,15.39)}=7.128, p=0.006\right.$; $F_{(1.602,11.21)}=9.103, p<0.005$, respectively; Fig. 3B). The ratio of time spent in the reward to the null zone (Fig. $3 \mathrm{C}$ ) increased $60 \%$ from day $1(\mathrm{M}=1.170)$ to day $2(\mathrm{M}=1.965$; $t_{(15)}=2.616, p=0.02$ ) demonstrating a clear preference for location of sucrose reward. This indicates that mice successfully acquired and executed the operant paradigm with $2 \mathrm{~d}$ of training, thus future experiments included two training days.

\section{Temperature-dependent tolerance: sex differences and reward salience}

Next, we investigated thermal tolerance in naive female and male mice by testing in the OPTA for 20 min with the null side set to $30^{\circ} \mathrm{C}$, and the reward side set to $10^{\circ} \mathrm{C}$, $15^{\circ} \mathrm{C}, 30^{\circ} \mathrm{C}, 40^{\circ} \mathrm{C}, 45^{\circ} \mathrm{C}$, or $50^{\circ} \mathrm{C}$, with $4 \%$ sucrose available in the reward zone. Temperatures were presented $24 \mathrm{~h}$ apart, in a pseudo-random order, over $6 \mathrm{~d}$. The values for each temperature were matched and means compared within and between sexes (Fig. 4A). There was a significant main effect of temperature $\left(F_{(5,70)}=14.62\right.$, $p<0.001$ ), with all mice displaying an aversion to the extreme temperatures as indicated by less time in reward zone. A significant main effect of $\operatorname{sex}\left(F_{(1,14)}=12.47\right.$, $p=0.003$ ) indicated that, compared with males, female mice overall spent more time in the reward zone, displaying a significantly higher tolerance to $40^{\circ} \mathrm{C}$ and $45^{\circ} \mathrm{C}$ compared with males in the OPTA (Tukey post hoc: $p=0.009$ and $p=0.01$, respectively). Within group, females showed a specific aversion only to $50^{\circ} \mathrm{C}$ compared with all other temperatures (Tukey post hoc: $p \leq 0.05$ ). Males tolerated $15^{\circ} \mathrm{C}$ significantly more than $40^{\circ} \mathrm{C}, 45^{\circ} \mathrm{C}$, and $50^{\circ} \mathrm{C}$ (Tukey post hoc: $p \leq 0.005)$ and also tolerated $30^{\circ} \mathrm{C}$ significantly more than $45^{\circ} \mathrm{C}$ and $50^{\circ} \mathrm{C}$ (Tukey post hoc: $p \leq 0.01$ ). Representative heat maps are shown.

To assess the magnitude of reward on thermal tolerance, female and male mice were exposed to the protocol as above, however a $10 \%$ sucrose solution was used. Total time in reward zone was compared with that of the sex and age matched animals from the above experiment. 
Female mice exhibited less time in the reward zone under $10 \%$ sucrose conditions $\left(F_{(1,14)}=6.63, p=0.02\right.$; Fig. $\left.4 B\right)$. Representative heat maps of $4 \%$ and $10 \%$ sucrose conditions for females are shown. In contrast, in male mice (Fig. $4 C)$ the interaction effect between sucrose concentration and temperature was significant $\left(F_{(5,65)}=3.2, p=0.012\right)$, indicating that increased reward led to increased thermal tolerance. Male mice specifically spent more time in the $10 \%$ reward zone compared with the $4 \%$ zone at $40^{\circ} \mathrm{C}$ $(p=0.002$, Sidak's post hoc). Representative heat maps of $4 \%$ and $10 \%$ sucrose conditions for males at $30 / 40^{\circ} \mathrm{C}$ are shown below.

We next established whether $4 \%$ sucrose was sufficiently motivating for male mice to spend time in the reward zone. Male mice spent more time in the reward zone when $4 \%$ sucrose was present relative to an empty bottle $\left(t_{(18)}=2.06, p=0.05\right.$; Fig. $\left.4 D\right)$. A significant positive correlation between time in reward zone and sucrose consumption was observed $\left(r_{18}=0.83, p=0.003\right.$; Fig. 4E). An acquisition and extinction protocol was conducted with both floors set to $30^{\circ} \mathrm{C}$. On day 1 , mice were given a 10-min free exploration of the OPTA with both bottles empty to introduce the environment. This was followed $24 \mathrm{~h}$ later (day 2) by a 30 -min acquisition period, in which $4 \%$ sucrose was available in the reward zone. Mice were returned to the apparatus $24 \mathrm{~h}$ later (day 3) for extinction learning wherein both bottles were empty. On day 3 , removal of the reward significantly decreased reward zone time from that of day $2\left(t_{(7)}=2.67\right.$, $p=0.03$; Fig. 4F). These data indicate that male mice were incentivized to access the reward zone to consume sucrose.

\section{Thermal tolerance in a model of neuropathic injury}

The radiant heat withdrawal assay was performed $7 d$ after $\mathrm{CCl}$ or sham surgery to assess the effect of neuropathic injury on thermal nociception. Mice with $\mathrm{CCl}$ displayed thermal hyperalgesia as indicated by reduced withdrawal latency compared with sham animals $\left(t_{(14)}=\right.$ $5.40, p<0.0001$; Fig. 5A). The OPTA was used to further assess the impact of neuropathic injury on thermal tolerance (heat maps at $30 / 40^{\circ} \mathrm{C}$ below; Fig. $5 B$ ). We observed a main effect of temperature $\left(F_{(5,70)}=22.19, p=0.0001\right)$, with $\mathrm{CCl}$ and Sham groups displaying an aversion to cold and hot temperatures. There was also a main effect of $\mathrm{CCl}\left(F_{(1,14)}=9.41, p=0.01\right)$, surprisingly, $\mathrm{CCl}$ animals displayed an increase in time spent in the reward zone across all temperatures. Total time spent in the reward zone across all temperatures showed that animals with $\mathrm{CCl}$ spent more time overall in the reward zone versus sham $\left(t_{(5)}=3.24, p=0.02\right.$; Fig. $\left.5 \mathrm{C}\right)$. Total distance traveled was assessed to test for mobility differences between groups during testing (tracking plots at $30 / 15^{\circ} \mathrm{C}$ below; Fig. 5D). There was a trend for main effect of $\mathrm{CCl}\left(F_{(1,14)}=\right.$ $4.22, p=0.06)$ and a main effect of temperature $\left(F_{(5,70)}=\right.$ $5.84, p<0.001)$. Total distance traveled across all temperatures showed that $\mathrm{CCl}$ animals exhibited increased distance traveled compared with sham $\left(t_{(5)}=4.78\right.$, $p=0.01$; Fig. $5 E$ ). Taken together, these results show that despite the presence of neuropathic injury-induced heat
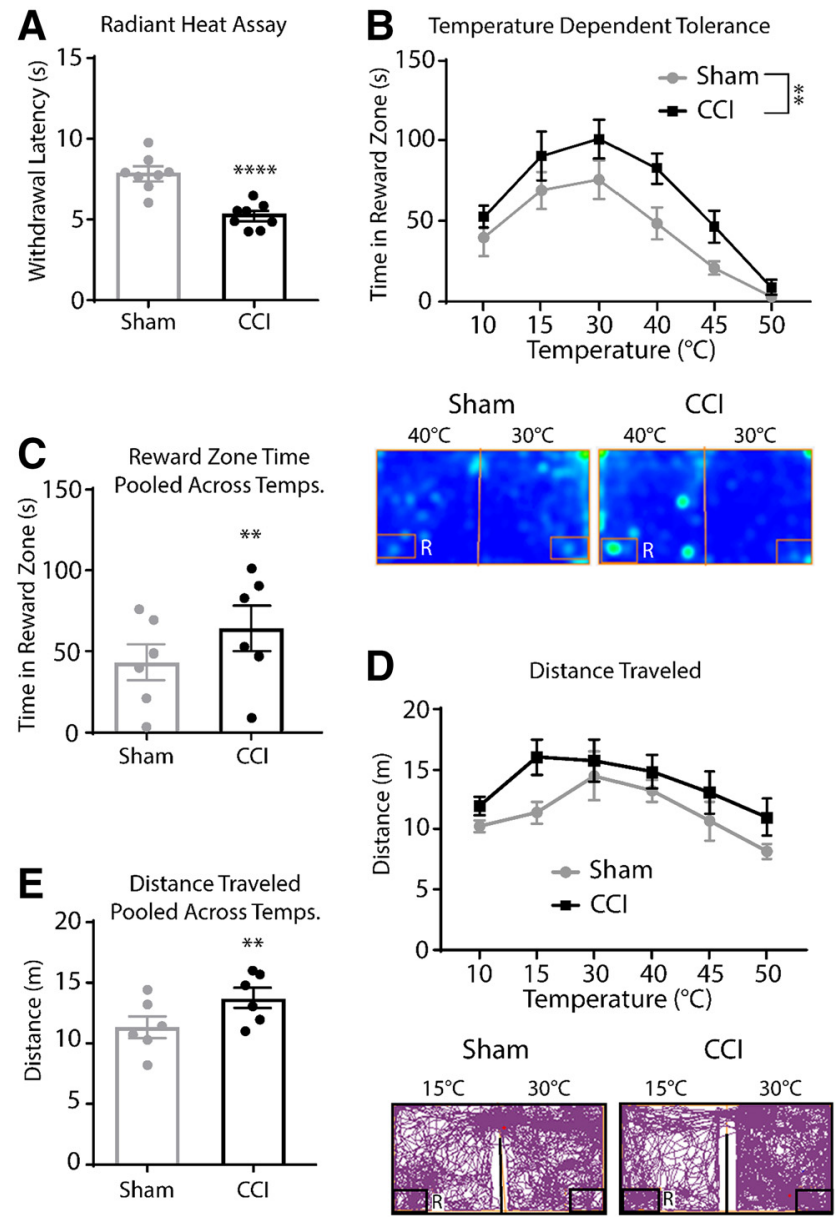

Figure 5. Neuropathic pain increased time in reward zone and mobility in the OPTA. $\boldsymbol{A}$, The radiant heat withdrawal assay showed decreased paw withdrawal latency in $\mathrm{CCl}$ versus sham ( $n=8$ per group), unpaired $t$ test (two-tailed). $\boldsymbol{B}$, High and low temperatures were aversive for both $\mathrm{CCl}$ and sham animals, although $\mathrm{CCl}$ animals spent more time in the reward zone across even aversive temperatures, two-way ANOVA, Sidak's correction. Below, Representative heat maps at $30 / 40^{\circ} \mathrm{C}$ test. $\boldsymbol{C}$, Analysis of pooled time in the reward zone, paired $t$ test, (two-tailed). $\boldsymbol{D}, \mathrm{CCl}$ presented with greater distance traveled throughout testing, two-way ANOVA, Sidak's correction. Below, Representative track plots at $30 / 15^{\circ} \mathrm{C}$ test. $\boldsymbol{E}$, Analysis of pooled distance traveled, paired $t$ test, (two-tailed). Data are presented as the mean $\pm \mathrm{SEM} ; * * p \leq 0.01$, $* * * * p \leq 0.001$. $\mathrm{R}=$ reward zone.

hyperalgesia, the capacity to tolerate even aversive temperatures was enhanced during neuropathic pain in the presence of a reward.

\section{Effects of clonidine in $\mathrm{CCl}$ model of neuropathic pain}

The $\alpha 2$-adrenergic agonist clonidine or equivalent volume of vehicle ( $0.9 \%$ saline) was tested to evaluate the effect of analgesia on time in reward zone in the CClinduced model of neuropathic pain versus sham surgery. To mitigate a potential ceiling effect and enhance detection, $45^{\circ} \mathrm{C}$ was chosen as the challenge temperature for testing with clonidine. 

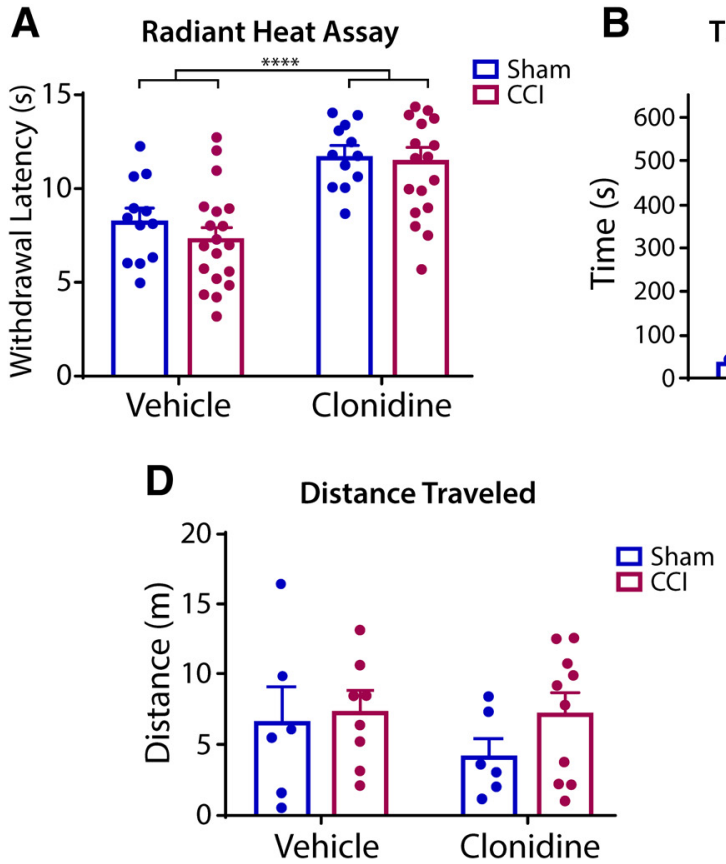

B Time in $45^{\circ} \mathrm{C}$ Reward Zone

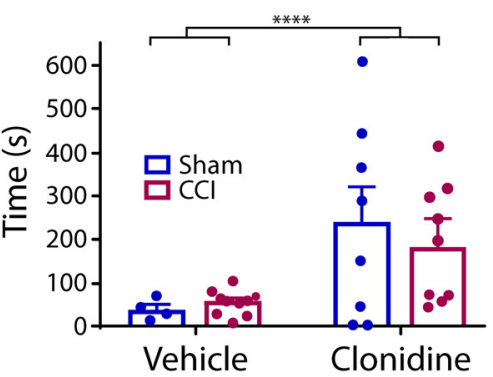

C

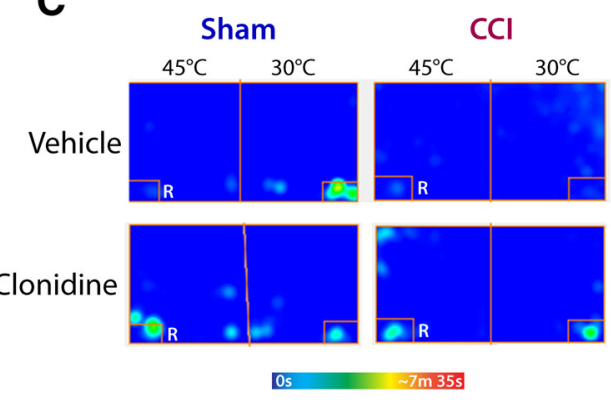

E

Vehicle
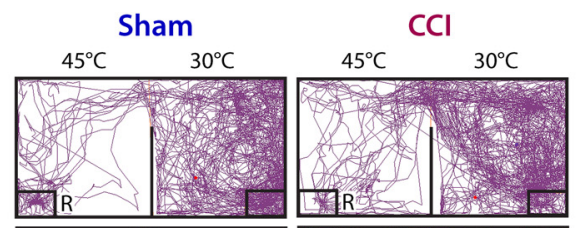

Clonidine

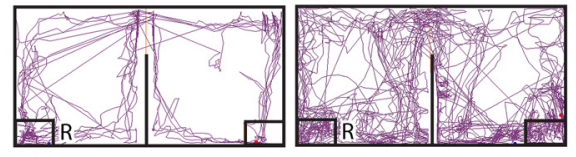

Figure 6. Neuropathic pain and clonidine in the OPTA. $\boldsymbol{A}$, The radiant heat withdrawal assay showed clonidine increased withdraw threshold regardless of neuropathic pain, ( $n=12$ per group), two-way ANOVA, Sidak's correction. $\boldsymbol{B}$, Clonidine increased time in reward zone in noxious heat chamber. Sham vehicle $(n=4)$; sham clonidine $(n=8)$; CCl vehicle $(n=10)$; $\mathrm{CCl}$ clonidine $(n=9)$, two-way ANOVA, Sidak's correction. $\boldsymbol{C}$, Representative heat maps of vehicle and clonidine treatment in sham and CCl. $\boldsymbol{D}$, Neither clonidine nor $\mathrm{CCl}$ influence distance traveled, two-way ANOVA, Sidak's correction. $\boldsymbol{E}$, Representative tracking plots of vehicle and clonidine treatment in sham and $\mathrm{CCl}$ surgeries. Sham vehicle $(n=6)$; sham clonidine $(n=6)$; CCl vehicle $(n=8)$; $\mathrm{CCl}$ clonidine $(n=10)$. R = reward zone. Data are presented as the mean \pm SEM; $* * * * p \leq 0.001$.

Threshold for withdrawal to radiant heat (Fig. 6A) was tested $7 \mathrm{~d}$ after $\mathrm{CCl}$. Tests conducted $30-60$ min after intrathecal injection showed no main effect of $\mathrm{CCl} .\left(F_{(1,29)}=\right.$ $0.68, p=0.41)$. A main effect of clonidine $\left(F_{(1,29)}=40.25\right.$, $p<0.0001$ ) was found. Both sham and CCl animals administered clonidine exhibited an increased withdrawal latency compared with vehicle $\left(t_{(30)}=6.72, p<0.001\right.$, data not shown).

When assessed for effects on thermal tolerance (Fig. 6B), clonidine resulted in an increase in time in the noxious reward zone in both $\mathrm{CCl}$ and sham animals compared with vehicle $\left(F_{(1,27)}=9.51, p=0.005\right)$, with no effect of $\mathrm{CCl}$ on time in the reward zone $\left(F_{(1,27)}=0.10, p=0.76\right)$. Representative heat maps are presented in Figure 6C. Analysis of distance traveled (Fig. $6 D$ ) revealed no main effect of clonidine $\left(F_{(1,26)}=0.74, p=0.40\right)$ or $\mathrm{CCl}\left(F_{(1,26)}=1.40\right.$, $p=0.25)$ compared with respective controls. Representative tracking plots are presented in Figure $6 E$. Taken together, these data indicate that clonidine has a robust effect on both thermal nociceptive threshold and tolerance to aversive temperature regardless of neuropathic injury state.

\section{Thermal tolerance in a model of inflammation}

The radiant heat withdrawal assay was conducted 24 , 48 , and $72 \mathrm{~h}$ after CFA or vehicle injection (Fig. 7A). The CFA group displayed significantly reduced latency to withdraw 24 and $48 \mathrm{~h}$ after injection compared with the vehicle group $\left(t_{(15)}=3.46, p=0.004 ; t_{(15)}=2.62, p=0.02\right.$, respectively), but did not show reduced withdrawal latency $72 \mathrm{~h}$ after injection $\left(t_{(15)}=1.6, p=0.13\right)$. Subsequent OPTA testing was therefore limited to $2 \mathrm{~d}$ post-CFA administration.

In temperature-dependent tolerance tests, there was a main effect of temperature on time spent in reward zone $\left(F_{(5,52)}=14.53, p<0.0001\right)$, but no main effect of CFA, indicating that CFA did not modify thermal pain tolerance $\left(F_{(1,52)}=0.80, p=0.37\right.$; heat maps at $30 / 40^{\circ} \mathrm{C}$ below; Fig. $7 B)$. Temperature resulted in a main effect on distance traveled $\left(F_{(5,52)}=7.53, p<0.001\right)$, but no main effect of CFA on distance was found $\left(F_{(1,52)}=0.20, p=0.65\right.$; tracking plots at $30 / 30^{\circ} \mathrm{C}$ below; Fig. $7 D$ ). These results indicate that within the OPTA, inflammatory state did not significantly alter the effects of temperature on reward zone time or distance traveled.

\section{Effects of meloxicam in CFA model of inflammation}

The effects of meloxicam, or equivalent volume of vehicle $(0.9 \%$ saline), were tested to evaluate the effect of analgesia on thermal threshold and time in reward zone at $40^{\circ} \mathrm{C}$ in the CFA-induced model of inflammatory pain. This temperature was chosen as it resulted in the greatest difference in temperature dependent tolerance tests in CFA versus control animals (Fig. $7 B$ ). Threshold for withdrawal to radiant heat (Fig. 8A) 40-80 min after treatment showed an interaction effect between plantar injection and treatment $\left(F_{(1,28)}=12.03, p=0.002\right)$, indicating that the effect of treatment on withdrawal depended on the type of injury. Specifically, CFA animals with vehicle treatment displayed 
A Radiant Heat Assay
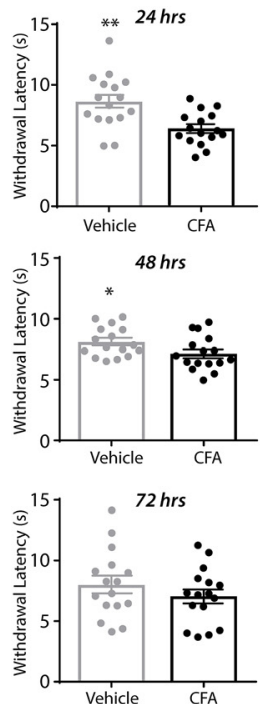

B Temperature Dependent Tolerance

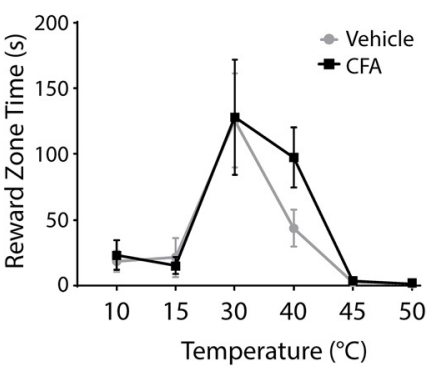

Vehicle

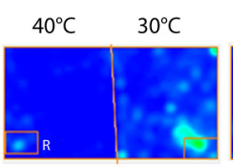

CFA

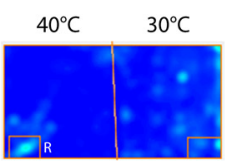

C

Distance Traveled

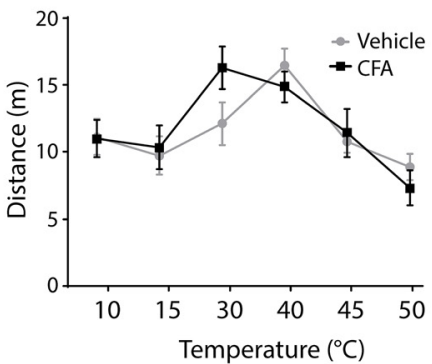

Vehicle

CFA
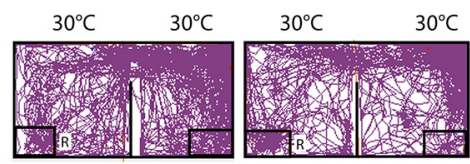

Figure 7. Inflammatory pain in the OPTA. $\boldsymbol{A}$, CFA $(n=16)$ resulted in reduced withdrawal latency compared with sham $(n=16)$ in the radiant heat withdrawal assay indicating the presence of hyperalgesia from CFA injection up to $48 \mathrm{~h}$ after injection, unpaired $t$ tests (two-tailed). B, CFA did not affect time in reward zone in the temperature-dependent tolerance test, two-way ANOVA, Sidak's correction. Below, Representative heat maps. C, CFA did not alter distance traveled at any specific temperature or across pooled temperatures, two-way ANOVA, Sidak's correction. Below, Representative track plots. R = reward zone. Data are presented as the mean \pm SEM; $* p \leq 0.05, * * p \leq 0.01$.

decreased withdrawal time compared with control animals with vehicle treatment $(p=0.0002$, Tukey's post hoc), control animals with meloxicam treatment $(p=0.003$, Tukey's post hoc), and CFA animals with meloxicam treatment $(p=0.002$, Tukey's post hoc). This indicates that the anti- hyperalgesic properties of meloxicam are apparent in the presence of inflammation only, and no additional reduction in hypersensitivity was seen as a result of meloxicam treatment in control animals as compared with vehicle treatment in control animals.
A Radiant Heat Assay

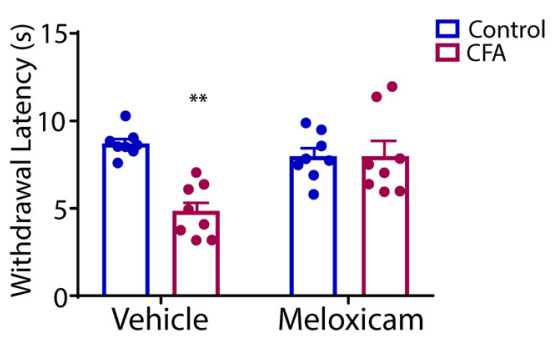

D

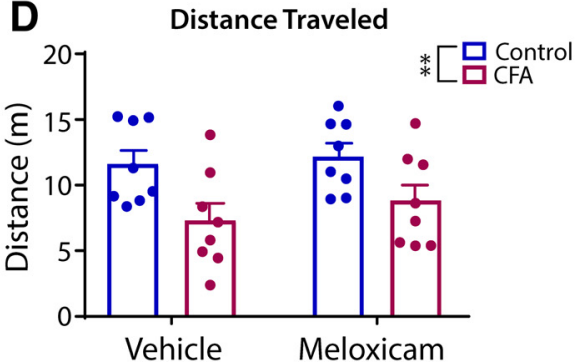

B Time in $40^{\circ} \mathrm{C}$ Reward Zone

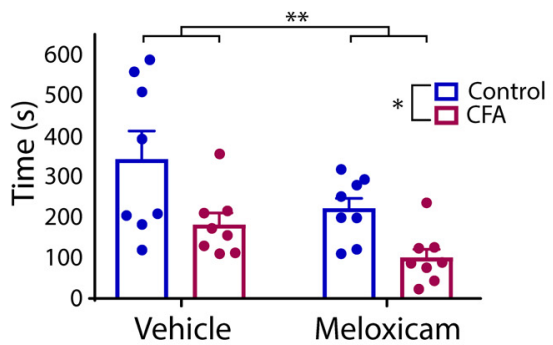

E

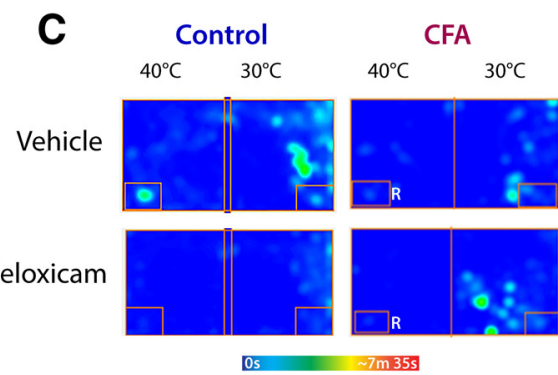

Vehicle
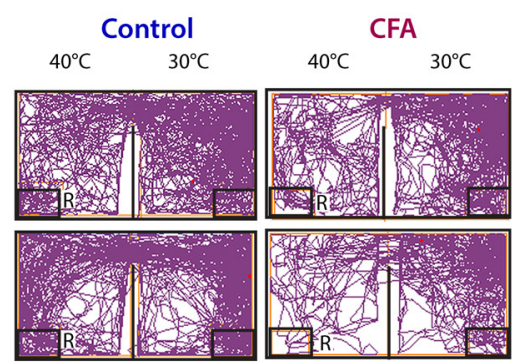

Figure 8. Meloxicam in a model of inflammatory pain in the OPTA. $\boldsymbol{A}$, There was a significant interaction between the effect of plantar injection and treatment on withdrawal latency in the radiant heat withdrawal assay, two-way ANOVA with Tukey's correction. B, Both CFA and meloxicam reduced time in reward zone. $\boldsymbol{C}$, Representative heat maps of vehicle and meloxicam treatment in control and CFA. D, CFA resulted in reduced distance traveled as compared with control, two-way ANOVA with Tukey's correction. $\boldsymbol{E}$, Representative track plots of vehicle and meloxicam in control and CFA. For all groups, $n=8$. $\mathrm{R}=$ reward zone. Data are presented as the mean $\pm \mathrm{SEM} ; * p \leq 0.05, * * p \leq 0.01$. 
When assessed for thermal tolerance using the OPTA (Fig. 8B), there was a main effect for plantar injection $\left(F_{(1,28)}=6.507, p=0.02\right)$ as well as treatment $\left(F_{(1,28)}=\right.$ $12.25, p=0.002)$. Representative heat maps are presented in Figure 8C. Overall, CFA-treated animals spent less time in the reward zone $(\mathrm{M}=32.86, \mathrm{SEM}=9.58)$ than control animals $(M=65.74$, SEM $=14.39)$, and meloxicam-treated animals spent less time in the reward zone $(M=37.31, S E M=14.04)$ than vehicle-treated animals $(M=61.28, S E M=18.84)$. Specifically, control animals with vehicle treatment spent more time in the reward zone than both CFA animals given vehicle $(p=0.04$, Tukey's post hoc) and CFA animals given meloxicam $(p=0.001$, Tukey's post hoc). Analysis of distance traveled (Fig. $8 D$ ) revealed a main effect of injection $\left(F_{(1,28)}=11.05, p=0.003\right)$, with CFA-injected mice traveling less $(M=10.05$, SEM $=0.99)$ than controls $(M=14.89$, $\mathrm{SEM}=0.41$ ). Specifically, vehicle-treated CFA animals traveled significantly less than meloxicam-treated control animals $(p=0.03$, Tukey's post hoc). Representative track plots are presented in Figure $8 E$. This indicates untreated CFA reduced mobility, but meloxicam itself does not affect mobility, thus likely does not account for reduced time in reward zone by meloxicam-treated animals. Overall, these data suggest that in the CFA model of inflammation, meloxicam is efficacious in reversing localized thermal hyperalgesia resulting from CFA, but is not effective in reversing or attenuating reduced thermal tolerance and may even promote lowered pain tolerance.

\section{Discussion}

Unsatisfactory translation of reflexive measures of nociception, in which the endpoint is withdrawal to a threshold stimulus, has led to a crisis and demand for new models to assess non-reflexive measures of pain in animals (Mogil, 2009; Mogil et al., 2010; King and Porreca, 2014; Vierck and Yezierski, 2015; Klinck et al., 2017). Pain tolerance is an integral component of the pain experience which has been defined as "the maximum intensity of a pain-producing stimulus that a subject is willing to accept in a given situation" (Loeser and Treede, 2008). Pain tolerance is a critical limiting factor in the ability of chronic pain patients to complete daily tasks, and selectively modulating this factor is a potential alternative approach to pain management. The underlying cells and circuits mediating pain tolerance have not been identified, but evidence suggests they overlap with supraspinal processes that subserve attention, response selection, and mood (Tölle et al., 1999; Tang et al., 2008).

Operant tests targeting supraspinally regulated affective, cognitive, and motivational processing of pain are increasingly used in pain research, including conditioned preference, place escape/avoidance, the mechanical conflict system (Harte et al., 2016), and the operant orofacial pain assay (Neubert et al., 2005). While these assays provide new and important ways to investigate animal behavior, the OPTA generates information not captured by these tests. Only the operant orofacial assay, like the OPTA, produces a measure of choice time engaged with an aversive stimulus. This more closely represents the daily choices an individual with chronic pain must make wherein repeated or lengthy engagement with known aversive actions must occur to achieve life goals. However, the operant orofacial assay demands greater training and nutrient deprivation, requires that animals be nude or shaved and therefore lack whiskers, a primary source of sensation, and is focused on the trigeminal system and therefore may not be appropriate for the more common spinally mediated models of pain.

The OPTA reward floor, set at temperatures above $35^{\circ} \mathrm{C}$ or below $25^{\circ} \mathrm{C}$, generated avoidance behavior indicative of an unpleasant somatosensory, affective, and motivational experience. Cutaneous thermosensation at somatic contact points with the floor is mediated by a heterogeneous population of primary afferent $\mathrm{A} \delta$ and $\mathrm{C}$ fibers, including thermosensitive nociceptors which activate at $\leq 28^{\circ} \mathrm{C}$ for cold and $\geq 37^{\circ} \mathrm{C}$ for heat (Green and Akirav, 2010; Schepers and Ringkamp, 2010). The central projections of these primary afferent fibers converge onto spinal neurons, including those forming the spinothalamic tract, which respond to thermal stimuli as well as noxious chemical and mechanical stimuli (Burstein et al., 1991; Zhang et al., 2006). Therefore, the aversive floor temperatures used in this study are likely encoded via thermo-nociceptive peripheral and central pathways that reach the brain.

Both male and female mice exhibited similar baseline preferences for temperature when no reward was present. Male and female mice also similarly acquired the operant paradigm during training in the OPTA. Interestingly, in the OPTA during challenge, female mice demonstrated increased heat pain tolerance compared with males. This previously unrecognized observation of sex differences on pain tolerance in mice does not match a human psychophysical study that showed added incentives to tolerate pain in the cold-pressor test increased tolerance similarly in both men and women (Lowery et al., 2003). This discrepancy could reflect differences in tolerance to heat versus cold, or species differences. In humans, females tend to exhibit lower tolerance scores than males on both cold pressor and contact heat tolerance tests, when conducted without manipulation of motivating factors (Fillingim et al., 2009; Forsythe et al., 2011; Bartley and Fillingim, 2013). However, female subjects showed enhanced heat adaptation on repeated trials compared with males (Hashmi and Davis, 2009, 2010), suggesting that females may exhibit greater tolerance to repeated heat, consistent with female mouse data from the OPTA.

Overall, female mice tend to exhibit higher sensitivity and more severe and lengthened responses to pain, and this is generally consistent with humans (Hurley and Adams, 2008). Inflammation affects afferent fibers in females more than males, specifically $\mathrm{C}$-fibers which result in increased nociceptive sensitivity (Rosen et al., 2017; Sorge and Strath, 2018). Neuropathic and inflammatory models have indicated that sex differences exist in neuroimmune and hormonal interactions that can lead to variable differences in pain behaviors (Sorge et al., 2015; Taves et al., 2016; Rosen et al., 2017). Of note, pre-clinical research regarding sex differences in pain tolerance is 
currently lacking. Our observations indicate that pain tolerance and hypersensitivity are regulated by separate mechanisms, and offer a path to investigate the neural processing of novel pain-related behaviors. Further investigation of pain tolerance to produce a better understanding of the dependence of pain coping capacity on sex, stimulus modality, and motivational cues is needed.

To determine whether ongoing pain modifies pain tolerance behavior, the OPTA was used to test mice with $\mathrm{CCl}-$ induced neuropathy. This unexpectedly revealed that neuropathic mice showed greater reward time and tolerance to aversive temperatures than sham. Previous animal studies of reward-seeking behavior under neuropathic conditions have shown mixed effects with some reporting a loss of reward-seeking behavior, or anhedonia (Goffer et al., 2013; Dellarole et al., 2014; Lee et al., 2015), or no change in motivational responses to reward (Urban et al., 2011; Okun et al., 2016). Neuropathic pain can alter descending inhibitory and facilitatory systems to alter threshold nociception (Ossipov et al., 2014; Patel et al., 2018; Chen and Heinricher, 2019), but how these systems might regulate pain tolerance is still unclear. Pain-evoked plasticity of neuromodulatory signals in reward circuits has implicated the nucleus accumbens and limbic forebrain structures in nociceptive responses (Sagheddu et al., 2015; Massaly et al., 2019). These and other supraspinal regions may contribute to the decision-making processes that occur during the OPTA. In contrast to the neuropathic model, CFA-induced inflammation did not alter time in the reward zone, or thermal tolerance, suggesting that the duration, intensity, or type of injury may be an important factor in pain tolerance regulation.

We hypothesized that analgesics may work differently on pain tolerance and nociceptive thresholds. Clonidine is often used in research models of neuropathic pain, due to its analgesic efficacy and lack of innate reward (King et al., 2009). We confirmed that clonidine reduced hypersensitivity to radiant heat, and additionally found that clonidine enhanced thermal tolerance in the OPTA. However, this enhanced thermal tolerance was present in both $\mathrm{CCl}$ and sham animals indicating that clonidine is a drug with effects that are not specific to pain, but rather a general suppression of somatosensation. Clonidine also possess sedative effects, but the lack of a reduced distance traveled by clonidine-treated mice indicates this was unlikely to be a factor here. Dry mouth and thirst have been reported as side effects of clonidine and cannot be ruled out as an influence of time in reward zone, although this is unlikely to result from intrathecal administration.

Consistent with the literature, CFA produced thermal hyperalgesia, that was attenuated by the NSAID meloxicam, without affecting mobility (Kolstad et al., 2012). In light of these results, it was surprising that pain tolerance was reduced in both CFA and control animals treated with meloxicam, as this suggests a decreased thermal tolerance mediated by the drug itself. Given there was no main effect of meloxicam on distance traveled, it is unlikely that the drug affected choice time in reward zone. While nausea cannot be ruled out as a contributing factor to reduced time in reward zone, meloxicam has a low gastrointestinal side effect profile (Ingrao et al., 2013) which is even less likely to occur with a single subcutaneous administration.

Taken together, these results suggest that while some NSAIDs exhibit anti-hyperalgesic properties, they may also limit the capacity to tolerate pain in some cases. Psychophysical studies in humans have shown mixed results of NSAIDs on pain tolerance. The cold pressor test failed to show that NSAIDs enhance tolerance (Jones et al., 1988), although enhanced tolerance was observed with NSAIDs in a burn model (Sycha et al., 2003). Meloxicam may act within the peripheral and central nervous system (Burian and Geisslinger, 2005; Novakova et al., 2014). In addition to the well-known anti-inflammatory effects of NSAIDS which we observed, NSAIDs also have been shown to modulate descending control of the spinal cord by preferentially disrupting C-fiber input while leaving $\mathrm{A} \delta$-nociceptor input intact (Waters and Lumb, 2008; Leith et al., 2014). It is possible that selective C-fiber suppression could lead to a relatively enhanced $A \delta$-mediated signal which consequently could limit pain tolerance.

In addition to traditional analgesics, sucrose itself has been reported to elicit analgesic effects, which may have contributed to some of the results. However, these effects are largely found only in pediatric subjects with varying efficacy and would not be expected to interfere with the decision to cross the reward side floor which precedes sucrose consumption (Kakeda, 2010; Slater et al., 2010; Wilson-Smith, 2011; Shahlaee et al., 2013).

Using the OPTA, we have identified previously uncharacterized, non-reflexive behavioral outputs of neuropathic and inflammatory pain models in male mice. Our observations indicate that hypersensitivity does not predict decreased pain tolerance, and that analgesics that reduce hypersensitivity may not necessarily enhance pain tolerance. Affective, cognitive, and motivational processing required for pain coping is thought to be mediated through higher-order neurons in regions such as the anterior cingulate, amygdala, and nucleus accumbens (Apkarian et al., 2005; Lee and Tracey, 2013). These regions contribute to a network that dictates avoidance behaviors, catastrophizing, and pain fear, which are fundamentally distinct from threshold reactions and are critical to the chronification of pain (Nees and Becker, 2018). An important modulator of these networks may be the type or duration of injury, as animals with neuropathic injury exhibited altered pain tolerance, while animals with inflammatory injury exhibited no change in pain tolerance. The $\mathrm{CCl}$ neuropathic model is more somatically extensive and longer lasting than CFA inflammatory model and likely results in greater recruitment and enhanced plasticity of pain-related circuitry which, in turn could generate a more robust compensatory response from descending pain-inhibitory pathways (Ossipov et al., 2014). A major goal of this study was to develop a complimentary tool to open new investigations into the supraspinal systems that contribute to pain tolerance. The OPTA can establish baseline thermal tolerance, measured as choice time in a thermally aversive reward zone, and can be used to examine how this thermal tolerance is altered in models of injury, psychiatric 
disorders, stress, or disease. Currently, findings in this study regarding pain and analgesia can only be applied to male mice. The unexpected divergence between males and females in temperature dependent tolerance indicates that female mice, despite possessing similar thermal preferences to males, require different testing conditions, a pursuit of future experiments. The OPTA was designed to test mice; however, minor modifications can be made to accommodate larger rodents. It is worth noting that the OPTA is not suited for pain models presenting with severely reduced mobility.

Pain tolerance is highly plastic within individuals and is altered by stress, exercise, drug use, age, race, and social situations (Rhudy and Meagher, 2000, 2003; Edwards et al., 2001; Kállai et al., 2004; Shavers et al., 2010; Lautenbacher et al., 2017; Merkle et al., 2018; Sluka et al., 2018). Longitudinal studies may be particularly useful in identifying critical time points to better understand the development of altered pain tolerance after injury. Ultimately, the OPTA can be used in tandem with many techniques in neurobiology including optogenetics and chemogenetics to identify and manipulate the neuroanatomical substrates that regulate pain tolerance in the brain. Preclinical testing of pain tolerance may lead to novel efficacious and cost-effective strategies for pain management in patients.

\section{References}

Apkarian AV, Bushnell MC, Treede RD, Zubieta JK (2005) Human brain mechanisms of pain perception and regulation in health and disease. Eur J Pain 9:463-463.

Bartley EJ, Fillingim RB (2013) Sex differences in pain: A brief review of clinical and experimental findings. Br J Anaesth 111:52-58.

Bautista DM, Siemens J, Glazer JM, Tsuruda PR, Basbaum Al, Stucky CL, Jordt SE, Julius D (2007) The menthol receptor TRPM8 is the principal detector of environmental cold. Nature 448:204208.

Bennett GJ, Xie YK (1988) A peripheral mononeuropathy in rat that produces disorders of pain sensation like those seen in man. Pain 33:87-107.

Burian M, Geisslinger G (2005) COX-dependent mechanisms involved in the antinociceptive action of NSAIDs at central and peripheral sites. Pharmacol Ther 107:139-154.

Burstein R, Dado RJ, Cliffer KD, Giesler GJ (1991) Physiological characterization of spinohypothalamic tract neurons in the lumbar enlargement of rats. J Neurophysiol 66:261-284.

Cheah M, Fawcett JW, Andrews MR (2017) Assessment of thermal pain sensation in rats and mice using the Hargreaves test. BioProtocol 7:e2506.

Chen Q, Heinricher MM (2019) Descending control mechanisms and chronic pain. Curr Rheumatol Rep 21:13.

Dart RC, Surratt HL, Cicero TJ, Parrino MW, Severtson SG, BucherBartelson B, Green JL (2015) Trends in opioid analgesic abuse and mortality in the United States. N Engl J Med 372:241-249.

Dellarole A, Morton P, Brambilla R, Walters W, Summers S, Bernardes D, Grilli M, Bethea JR (2014) Neuropathic pain-induced depressive-like behavior and hippocampal neurogenesis and plasticity are dependent on TNFR1 signaling. Curr Rheumatol Rep 41:65-81.

Edwards CL, Fillingim RB, Keefe F (2001) Race, ethnicity and pain. Pain 94:133-137.

Fairbanks CA (2003) Spinal delivery of analgesics in experimental models of pain and analgesia. Adv Drug Deliv Rev 55:1007-1041.
Fendrich R, Hutsler J, Gazzaniga M (2004) Visual and tactile interhemispheric transfer compared with the method of Poffenberger. Exp Brain Res 158:67-74.

Fillingim RB, King CD, Ribeiro-Dasilva MC, Rahim-Williams B, Riley $J L$ (2009) Sex, gender, and pain: A review of recent clinical and experimental findings. J Pain 10:447-485.

Forsythe LP, Thorn B, Day M, Shelby G (2011) Race and sex differences in primary appraisals, catastrophizing, and experimental pain outcomes. J Pain 12:563-572.

Goffer Y, Xu D, Eberle SE, D'amour J, Lee M, Tukey D, Froemke RC, Ziff EB, Wang J (2013) Calcium-permeable AMPA receptors in the nucleus accumbens regulate depression-like behaviors in the chronic neuropathic pain state. J Neurosci 33:19034-19044.

Green BG, Akirav C (2010) Threshold and rate sensitivity of lowthreshold thermal nociception. Eur J Neurosci 31:1637-1645.

Hargreaves K, Dubner R, Brown F, Flores C, Joris J (1988) A new and sensitive method for measuring thermal nociception in cutaneous hyperalgesia. Pain 32:77-88.

Harte SE, Meyers JB, Donahue RR, Taylor BK, Morrow TJ (2016) Mechanical conflict system: A novel operant method for the assessment of nociceptive behavior. PLoS One 11:e0150164.

Hashmi JA, Davis KD (2009) Women experience greater heat pain adaptation and habituation than men. Pain 145:350-357.

Hashmi JA, Davis KD (2010) Effects of temperature on heat pain adaptation and habituation in men and women. Pain 151:737-743.

Hurley RW, Adams MCB (2008) Sex, gender, and pain: An overview of a complex field. Anesth Analg 107:309-317.

Hylden JL, Wilcox GL (1980) Intrathecal morphine in mice: A new technique. Eur J Pharmacol 67:313-316.

Ingrao JC, Johnson R, Tor E, Gu Y, Litman M, Turner PV (2013) Aqueous stability and oral pharmacokinetics of meloxicam and carprofen in male C57BL/6 mice. J Am Assoc Lab Anim Sci 52:533-559.

Jirkof P (2014) Burrowing and nest building behavior as indicators of well-being in mice. J Neurosci Methods 234:139-146.

Jones SF, Mcquay HJ, Moore RA, Hand CW (1988) Cox-dependent mechanisms involved in the antinociceptive action in NSAIDs at central and peripheral sites. Pain 34:117-155.

Julius D (2013) TRP channels and pain. Annu Rev Cell Dev Biol 29:355-384.

Kakeda T (2010) Potential of sucrose-induced analgesia to relieve pain in male adults: A preliminary study. Jpn J Nurs Sci 7:169-173.

Kállai I, Barke A, Voss U (2004) The effects of experimenter characteristics on pain reports in women and men. Pain 112:142-147.

Kandasamy R, Calsbeek JJ, Morgan MM (2016) Home cage wheel running is an objective and clinically relevant method to assess inflammatory pain in male and female rats. J Neurosci Methods 263:115-122.

King T, Porreca F (2014) Preclinical assessment of pain: Improving models in discovery research. Curr Top Behav Neurosci 20:101120.

King T, Vera-Portocarrero L, Gutierrez T, Vanderah TW, Dussor G, Lai J, Fields HL, Porreca F (2009) Unmasking the tonic-aversive state in neuropathic pain. Nat Neurosci 12:1364-1366.

Klinck MP, Mogil JS, Moreau M, Lascelles BDX, Flecknell PA, Poitte T, Troncy E (2017) Translational pain assessment: Could natural animal models be the missing link? Pain 158:1633-1646.

Kolstad AM, Rodriguis RM, Kim CJ, Hale LP (2012) Effect of pain management on immunization efficacy in mice. J Am Assoc Lab Anim Sci 51:448-457.

Labuda CJ, Fuchs PN (2000) A behavioral test paradigm to measure the aversive quality of inflammatory and neuropathic pain in rats. Exp Neurol 163:490-494.

Langford DJ, Bailey AL, Chanda ML, Clarke SE, Drummond TE, Echols S, Glick S, Ingrao J, Klassen-Ross T, Lacroix-Fralish ML, Matsumiya L, Sorge RE, Sotocinal SG, Tabaka JM, Wong D, van den Maagdenberg AM, Ferrari MD, Craig KD, Mogil JS (2010) Coding of facial expressions of pain in the laboratory mouse. Nat Methods 7:447-449. 
Lautenbacher S, Peters JH, Heesen M, Scheel J, Kunz M (2017) Age changes in pain perception: A systematic-review and meta-analysis of age effects on pain and tolerance thresholds. Neurosci Biobehav Rev 75:104-113.

Lee MC, Tracey I (2013) Imaging pain: a potent means for investigating pain mechanisms in patients. Br J Anaesth 111:64-72.

Lee M, Manders TR, Eberle SE, Su XC, D 'amour J, Yang XR, Lin HY, Deisseroth K, Froemke RC, Wang XJ (2015) Activation of corticostriatal circuitry relieves chronic neuropathic pain. J Neurosci 35:5247-5249.

Leith JL, Wilson AW, You HJ, Lumb BM, Donaldson LF (2014) Periaqueductal grey cyclooxygenase-dependent facilitation of Cnociceptive drive and encoding in dorsal horn neurons in the rat. $J$ Physiol 592:5093-5107.

Lewis SR, Ahmed S, Dym C, Khaimova E, Kest B, Bodnar RJ (2005) Inbred mouse strain survey of sucrose intake. $\mathrm{Br} \mathrm{J}$ Anaesth 85:546-556.

Loeser JD, Treede RD (2008) The Kyoto protocol of IASP basic pain terminology. Pain 137:473-477.

Lowery D, Fillingim RB, Wright RA (2003) Sex differences and incentive effects on perceptual and cardiovascular responses to cold pressor pain. Psychosom Med 65:284-291.

Massaly N, Copits BA, Wilson-Poe AR, Hipólito L, Markovic T, Yoon HJ, Liu S, Walicki MC, Bhatti DL, Sirohi S, Klaas A, Walker BM, Neve R, Cahill CM, Shoghi KI, Gereau RW, McCall JG, Al-Hasani $\mathrm{R}$, Bruchas MR, Morón JA (2019) Pain-induced negative affect is mediated via recruitment of the nucleus accumbens kappa opioid system. Neuron 102:564-510.

Institute of Medicine (2011) Relieving pain in America: a blueprint for transforming prevention, care, education, and research. Washington, DC: The National Academies Press.

Melzack R (1999) From the gate to the neuromatrix. Pain 6:121-126.

Merkle SL, Sluka KA, Frey-Law LA (2018) The interaction between pain and movement. $\mathrm{J}$ Hand Ther. Advance online publication. Retrieved July 16, 2018. doi:10.1016/j.jht.2018.05.001.

Mogil JS (2009) Animal models of pain: progress and challenges. Nat Rev Neurosci 10:283-294.

Mogil JS, Davis KD, Derbyshire SW (2010) The necessity of animal models in pain research. Pain 151:12-17.

National Research Council (U.S.) (2011) Guide for the care and use of laboratory animals. Washington, DC: National Academies Press.

Nees F, Becker S (2018) Psychological processes in chronic pain: influences of reward and fear learning as key mechanisms - behavioral evidence, neural circuits, and maladaptive changes. Neuroscience 387:72-84.

Neubert JK, Widmer CG, Malphurs W, Rossi HL, Vierck CJ, Caudle RM (2005) Use of a novel thermal operant behavioral assay for characterization of orofacial pain sensitivity. Pain 116:386-395.

Novakova I, Subileau EA, Toegel S, Gruber D, Lachmann B, Urban E, Chesne C, Noe CR, Neuhaus W (2014) Transport rankings of nonsteroidal antiinflammatory drugs across blood-brain barrier in vitro models. PLoS One 9:e86806.

O'Brien DE, Alter BJ, Satomoto M, Morgan CD, Davidson S, Vogt SK, Norman ME, Gereau GB, Demaro JA, Landreth GE, Golden JP, Gereau RW (2015) ERK2 alone drives inflammatory pain but cooperates with ERK1 in sensory neuron survival. J Neurosci 35:9491-9507.

Okun A, McKinzie DL, Witkin JM, Remeniuk B, Husein O, Gleason SD, Oyarzo J, Navratilova E, McElroy B, Cowen S, Kennedy JD, Porreca F (2016) Hedonic and motivational responses to food reward are unchanged in rats with neuropathic pain. Pain 157:27312738.

Ossipov MH, Morimura K, Porreca F (2014) Descending pain modulation and chronification of pain. Curr Opin Support Palliat Care 8:143-151.

Patel R, Qu C, Xie JY, Porreca F, Dickenson AH (2018) Selective deficiencies in descending inhibitory modulation in neuropathic rats. Pain 159:1887-1899.
Price DD (2000) Psychological and neural mechanisms of the affective dimension of pain. Science 288:1769-1772.

Rhudy JL, Meagher MW (2000) Fear and anxiety: divergent effects on human pain thresholds. Pain 84:65-75.

Rhudy JL, Meagher MW (2003) Negative affect: effects on an evaluative measure of human pain. Pain 104:617-626.

Rice ASC, Smith BH, Blyth FM (2016) Pain and the global burden of disease. Pain 157:791-796.

Rosen S, Ham B, Mogil JS (2017) Sex differences in neuroimmunity and pain. J Neurosci Res 95:500-508.

Rudd RA, Aleshire N, Zibbell JE, Matthew GR (2016) Increases in drug and opioid overdose deaths - United States, 2000-2014. Curr Opin Support Palliat Care 16:1323-1327.

Sagheddu C, Aroni S, De Felice M, Lecca S, Luchicchi A, Melis M, Muntoni AL, Romano R, Palazzo E, Guida F, Maione S, Pistis M (2015) Enhanced serotonin and mesolimbic dopamine transmissions in a rat model of neuropathic pain. Neuropharmacology 97:383-393.

Schepers RJ, Ringkamp M (2010) Thermoreceptors and thermosensitive afferents. Neurosci Biobehav Rev 34:177-184.

Shahlaee A, Farahanchi A, Javadi S, Delfan B, Dehpour AR (2013) Sucrose-induced analgesia in mice: role of nitric oxide and opioid receptor-mediated system. Indian J Pharmacol 45:593-596.

Shavers VL, Bakos A, Sheppard VB (2010) Race, ethnicity, and pain among the U.S. adult population. J Health Care Poor Underserved 21:177-220.

Slater R, Cornelissen L, Fabrizi L, Patten D, Yoxen J, Worley A, Boyd S, Meek J, Fitzgerald M (2010) Oral sucrose as an analgesic drug for procedural pain in newborn infants: a randomised controlled trial. Lancet 376:1225-1232.

Sluka KA, Frey-Law L, Hoeger BM (2018) Exercise-induced pain and analgesia? Underlying mechanisms and clinical translation. Pain 159:S91-S97.

Sorge RE, Strath LJ (2018) Sex differences in pain responses. Curr Opin Physiol 6:75-81.

Sorge RE, Mapplebeck JCS, Rosen S, Beggs S, Taves S, Alexander JK, Martin LJ, Austin J-S, Sotocinal SG, Chen D, Yang M, Shi XQ, Huang H, Pillon NJ, Bilan PJ, Tu Y, Klip A, Ji R-R, Zhang J, Salter MW, Mogil JS (2015) Different immune cells mediate mechanical pain hypersensitivity in male and female mice. Nat Neurosci 18:1081-1083.

Stone LS, German JP, Kitto KF, Fairbanks CA, Wilcox GL (2014) Morphine and Clonidine Combination Therapy Improves Therapeutic Window in Mice: Synergy in Antinociceptive but Not in Sedative or Cardiovascular Effects. PLoS One 9:e109903.

Sycha T, Gustorff B, Lehr S, Tanew A, Eichler HG, Schmetterer L (2003) A simple pain model for the evaluation of analgesic effects of NSAIDs in healthy subjects. $\mathrm{Br} \mathrm{J}$ Clin Pharmacol 56:165-172.

Tang NKY, Salkovskis PM, Hodges A, Wright KJ, Hanna M, Hester J (2008) Effects of mood on pain responses and pain tolerance: an experimental study in chronic back pain patients. Pain 138:392401.

Taves S, Berta T, Liu DL, Gan S, Chen G, Kim YH, Van de Ven T, Laufer S, Ji RR (2016) Spinal inhibition of p38 MAP kinase reduces inflammatory and neuropathic pain in male but not female mice: sex-dependent microglial signaling in the spinal cord. Brain Behav Immun 55:70-81.

Tékus V, Horváth Á, Hajna Z, Borbély É, Bölcskei K, Boros M, Pintér E, Helyes Z, Pethó G, Szolcsányi J (2016) Noxious heat threshold temperature and pronociceptive effects of allyl isothiocyanate (mustard oil) in TRPV1 or TRPA1 gene-deleted mice. Life Sci 154:66-74.

Tölle TR, Kaufmann T, Siessmeier T, Lautenbacher S, Berthele A, Munz F, Zieglgänsberger W, Willoch F, Schwaiger M, Conrad B, Bartenstein P (1999) Region-specific encoding of sensory and affective components of pain in the human brain: a positron emission tomography correlation analysis. Ann Neurol 45:4047. 
Urban R, Scherrer G, Goulding EH, Tecott LH, Basbaum Al (2011) Behavioral indices of ongoing pain are largely unchanged in male mice with tissue or nerve injury-induced mechanical hypersensitivity. Pain 152:990-1000.

Vierck CJ, Yezierski RP (2015) Comparison of operant escape and reflex tests of nociceptive sensitivity. Neurosci Biobehav Rev 51:223-242.

Vierck CJ, Hansson PT, Yezierski RP (2008) Clinical and pre-clinical pain assessment: are we measuring the same thing? Pain 135:710.

Walczak JS, Beaulieu P (2006) Comparison of three models of neuropathic pain in mice using a new method to assess cold allodynia: the double plate technique. Neurosci Lett 399:240-244.
Waters AJ, Lumb BM (2008) Descending control of spinal nociception from the periacqueductal grey distinguishes between neurons with and without C-fibre inputs. Pain 134:32-40.

Wilson-Smith EM (2011) Procedural pain management in neonates, infants and children. Rev Pain 5:4-12.

Woolf CJ (1984) Long term alterations in the excitability of the flexion reflex produced by peripheral tissue injury in the chronic decerebrate rat. Pain 18:325-343.

Zhang X, Davidson S, Giesler GJ (2006) Thermally identified subgroups of marginal zone neurons project to distinct regions of the ventral posterior lateral nucleus in rats. J Neurosci 26:5215-5223.

Zheng J (2013) Molecular mechanism of TRP channels. Compr Physiol 3:221-242. 